\title{
Fibre from nopal cactus (Opuntia ficus-indica) improves symptoms in irritable bowel syndrome in the short term: a pilot randomised-controlled trial
}

\author{
M. Rossi ${ }^{1}$, H.A. Taboada-Liceaga ${ }^{2}$, S. Gill ${ }^{1}$, M. Amieva-Balmori ${ }^{2}$, G.A. Hernández-Ramírez ${ }^{2}$, \\ J.F. Garcia-Mazcorro ${ }^{2}$, K. Whelan ${ }^{1}$ and J.M. Remes-Troche ${ }^{2}$ \\ ${ }^{1}$ King's College London, Department of Nutritional Sciences, London, UK and \\ ${ }^{2}$ Instituto de Investigaciones Médico-Biológicas, Universidad Veracruzana, Veracruz, Mexico.
}

Irritable bowel syndrome (IBS) is a major, growing public health problem affecting 5-10\% of adults worldwide. Dietary fibre has the potential to manage IBS symptoms through mechanisms including stool bulking, stool water holding, microbiome modification and short-chain fatty acid (SCFA) production ${ }^{(1)}$. However, the current evidence for the therapeutic potential of dietary fibre supplementation is conflicting, reflecting differences in dose and the limited understanding of the various types of dietary fibres previously investigated. Indeed, high doses of non-viscous, highly-fermentable fibres have been shown to exacerbate symptoms in IBS ${ }^{(1)}$. In contrast, nopal (Opuntia ficus-indica) a cactus plant fibre, offers a unique combination of viscous and slowly fermented fibres that may have therapeutic potential in IBS. The aim of this pilot study was to evaluate the dose-response effect of extracted nopal fibre powder on symptoms in IBS.

Sixty patients fulfilling Rome IV criteria for IBS were recruited to a 4-arm, single-blinded randomised controlled trial receiving either: nopal fibre $(10 \mathrm{~g} / \mathrm{d}, 20 \mathrm{~g} / \mathrm{d}$, or $30 \mathrm{~g} / \mathrm{d})$ or placebo $(30 \mathrm{~g} / \mathrm{d}$ dextrose) for seven days. The primary outcome was the global symptom question 'adequate symptom relief' (response, yes/no). Additional outcomes including symptom severity (IBS-severity scoring system [IBS-SSS], Gastrointestinal Symptom Rating Scale [GSRS]), stool frequency and consistency (Bristol Stool Form Scale), fasting breath hydrogen and methane (GastroCH4ECK) and stool SCFA (gas liquid chromatography). All outcomes were measured at baseline and at the end of the seven days.

Significantly more patients reported adequate relief of symptoms after $20 \mathrm{~g} / \mathrm{d}(87 \%, \mathrm{p}=0.008)$ and $30 \mathrm{~g} / \mathrm{d}(80 \%$, p $=0.025)$ of nopal fibre compared to placebo $(33 \%)$, but not after $10 \mathrm{~g} / \mathrm{d}(60 \%, \mathrm{p}=0.136)$. All fibre groups had a significant reduction in total GSRS compared to placebo $(\mathrm{p}=0.001)$. More patients receiving $20 \mathrm{~g} / \mathrm{d}$ nopal fibre $(67 \%)$ had a $>50 \%$ reduction in IBS-SSS compared to placebo $(20 \%, \mathrm{p}=0.027)$, but this did not reach significance with $10 \mathrm{~g} / \mathrm{d}(60 \%, \mathrm{p}=0.06)$ or $30 \mathrm{~g} / \mathrm{d}(60 \%, \mathrm{p}=0.06)$. There were no differences between groups in breath hydrogen and methane, stool frequency and consistency or stool SCFA.

Nopal fibre supplementation at dose of $20 \mathrm{~g} / \mathrm{d}$ was associated with short-term improvement in IBS symptoms. These results warrant an adequately powered clinical trial of longer duration with symptomatic, physiological and microbiological endpoints. If found to be effective this low cost, easy to implement dietary approach has the potential to improve IBS management across a wide range of populations.

1. Eswaran S, Muir J, Chey WD (2013) Am J Gastroenterol 108, 718-27. 